Иностранным инвесторам была обеспечена высокая степень гарантий безопасности их инвестиций.

$$
* * *
$$

1. https://ru.wikipedia.org/wiki/\%D0\%9D\%D0\%BE\%D0\%B2\%D1\%8B\%D0\%B5_\%D0\%B8\%D0\%BD\%D0 \%B4\%D1\%83\%D1\%81\%D1\%82\%D1\%80\%D0\%B8\%D0\%B0\%D0\%BB\%D1\%8C\%D0\%BD\%D1\%8B\% D0\%B5_\%D1\%81\%D1\%82\%D1\%80\%D0\%B0\%D0\%BD\%D1\%8B

2. http://textbook.news/ekonomika-mejdunarodnaya/obschaya-harakteristika-novyih-industrialnyih.html

3. http://banauka.ru/604.html

4. https://works.doklad.ru/view/IPd1sMxL1zc.html

5. https://ru.tradingeconomics.com/singapore/indicators

\title{
Попова Е.М. \\ Применение эффективных налоговых ставок в качестве инструмента оценки уровня налогообложения инвестиций
}

Читинский институт (филиал) Байкальского государственного университета (Россия, Чита)

doi:10.18411/spc-8-03-2018-11

idsp: 000001:spc-8-03-2018-11

\section{Аннотация}

Для определения налогового бремени, с которым могут столкнуться инвесторы, используются три вида налоговых ставок: законодательно установленная налоговая ставка, средняя эффективная налоговая ставка и предельная эффективная налоговая ставка. При планировании крупных или долгосрочных инвестиций в определенной стране наибольший интерес представляют средние эффективные ставки, а в случае расширения уже действующих инвестиционных проектов - предельные эффективные ставки. В статье приведены результаты сравнения уровня налогообложения инвестиций в странах «Большой двадцатки». Сделан вывод о том, что важными детерминантами предельных эффективных ставок выступают соотношение заемного и собственного капитала и налоговый режим, установленный для амортизационных отчислений.

Ключевые слова: инвестиции, средняя эффективная налоговая ставка, предельная эффективная налоговая ставка.

Налоговые аспекты инвестирования являются объектом острого научного интереса. Однако стоит признать, что наибольший вклад в изучение данной проблемы внесли зарубежные экономисты, в частности, Фуллертон, Гравелл, Макки, Бёрнхам и другие. При осуществлении зарубежных инвестиций компании, как правило, ориентируются на три типа налоговых ставок: законодательно установленная налоговая ставка (statutory rate), средняя эффективная налоговая ставка (average effective tax rate) и предельная эффективная налоговая ставка (marginal effective tax rate). Компании ориентируются на законодательно установленные ставки, когда реализуют налоговые стратегии по перемещению дохода из высоконалоговых юрисдикций в низконалоговые, где они не планируют инвестировать и не претендуют на соответствующие налоговые преференции (табл.1).

Таблица 1

Законодательно установленная налоговая ставка, \%

\begin{tabular}{|c|c|}
\hline Страна & Значение \\
\hline США & 39,1 \\
\hline Япония & 37 \\
\hline Аргентина & 35 \\
\hline
\end{tabular}




\begin{tabular}{|c|c|}
\hline ЮАР & 34,6 \\
\hline Франция & 34,4 \\
\hline Бразилия & 34 \\
\hline Индия & 32,5 \\
\hline Италия & 31,4 \\
\hline Германия & 30,2 \\
\hline Австралия & 30 \\
\hline Мексика & 30 \\
\hline Канада & 26,1 \\
\hline Китай & 25 \\
\hline Индонезия & 25 \\
\hline Южная Корея & 24,2 \\
\hline Соединенное Королевство & 24 \\
\hline Россия & 20 \\
\hline Саудовская Аравия & 20 \\
\hline Турция & 20 \\
\hline
\end{tabular}

Предприятия акцентируют внимание на средней эффективной ставке, когда планируют крупные или долгосрочные инвестиции в определенной стране. Бюджетный комитет Конгресса США подготовил доклад, в котором приведен рейтинг средних эффективных ставок в странах «Большой двадцатки»: ставки ранжируются с самой высокой (37\%) в Аргентине до самой низкой (10\%) в Соединенном Королевстве (табл.2).

Таблица 2

Средняя эффективная налоговая ставка, \%

\begin{tabular}{|c|c|}
\hline Страна & Значение \\
\hline Аргентина & 37,3 \\
\hline Индонезия & 36,4 \\
\hline США & 29 \\
\hline Япония & 27,9 \\
\hline Италия & 26,8 \\
\hline Индия & 25,6 \\
\hline ЮАР & 23,5 \\
\hline Бразилия & 22,3 \\
\hline Россия & 21,3 \\
\hline Южная Корея & 20,4 \\
\hline Мексика & 20,3 \\
\hline Франция & 20 \\
\hline Турция & 19,5 \\
\hline Китай & 19,1 \\
\hline Австралия & 17 \\
\hline Канада & 16,2 \\
\hline Германия & 14,5 \\
\hline Соединенное Королевство & 10,1 \\
\hline
\end{tabular}

По имеющимся данным в странах «Большой двадцатки» зарегистрировано около 49 тыс. американских компаний с наибольшим числом именно в Соединенном Королевстве [1]. Особого внимания заслуживает методология ее расчета. Дело в том, что средняя эффективная налоговая ставка является показателем ex post и определяется как отношение фактически уплаченных налогов на доход за год к величине фактически полученного дохода за этот же год. Однако в силу недоступности данных о величине налоговых обязательств и заработанном доходе в разрезе стран при расчете средней ставки по всем странам «Большой двадцатки», кроме США, вводятся некоторые 
допущения. Во-первых, для ее расчета используется особая категория бизнес-единиц, известная как «U.S.-ownedforeigncompany», то есть, для исчисления средней эффективной налоговой ставки в конкретной стране формируется список компаний, которые должны быть зарегистрированы в одной из стран «Большой двадцатки» и которые контролируются американскими корпорациями [1]. Во-вторых, поскольку не представляется возможным вычленить величину налогов и заработанного дохода в конкретной стране, средняя эффективная ставка определяется как отношение общей суммы налогов, уплаченных во всех странах, где функционирует мультинациональная компания, к совокупному «мировому» доходу. Другими словами, делается допущение, что деятельность компании сосредоточена в стране регистрации и, соответственно весь валовый доход, в том числе доход, освобожденный от налогообложения, и налоговые обязательства относятся на страну, где зарегистрирована данная компания. Безусловно, такие оценки является косвенными показателями налогового бремени, с которым столкнутся американские корпорации при осуществлении долгосрочных инвестиций в той или иной стране. В то же время более точные оценки получают при расчете средней эффективной налоговой ставки для США, где используются данные по так называемым «foreign-owned U.S. corporations», компаниям, которые зарегистрированы в США и которые контролируются зарубежными корпорациями. В этом случае подаваемые ими налоговые декларации позволяют определить величину дохода, источником которого стала деятельность в США, и величину налогов, уплаченных в бюджет США.

Наконец, предельная эффективная налоговая ставка является более информативной при принятии решений о расширении уже реализуемых в стране инвестиционных проектов. Изучению особенностей данного вида налоговых ставок будет посвящено дальнейшее содержание статьи. Предельная эффективная ставка для новых инвестиций - это прогнозная налоговая ставка, ставка ex ante, которая представляет собой отношение налогового клина к реальной отдаче капитала до налогообложения, которая есть ни что иное, как стоимость капитала.

$$
\operatorname{METR}=\frac{(c-\delta)-s}{c-\delta}, \text { где }
$$

METR - предельная эффективная налоговая ставка;

$\mathrm{c}-\delta$ - стоимость капитала;

$\mathrm{s}$ - средневзвешенная реальная доходность инвестиций, финансируемых собственным и заемным капиталом.

Предельная эффективная ставка позволяет учесть налоговые льготы, предусмотренные действующим налоговым законодательством, например, такие как инвестиционные налоговые кредиты, ускоренную амортизацию, вычеты процентов и уплаченных местных налогов на недвижимость. В свою очередь, под налоговым клином понимают разницу между реальным уровнем доходности до налогообложения и после налогообложения.

Расчет предельной эффективной налоговой ставки традиционно начинается с исчисления стоимости капитала по формуле, предложенной в 1967 г. Р. Холлем и Д. Джоргенсоном, в соответствии с которой стоимость капитала представляет собой реальный уровень рентабельности, который должен обеспечить безубыточность инвестиций [2]. Безубыточность инвестиций означает, что реальный уровень рентабельности инвестиций после налогообложения равен темпу инфляции в случае финансирования инвестиций собственными средствами, или стоимости заемных 
ресурсов при долговом финансировании. Особенность показателя «стоимость капитала» состоит в том, что при его расчете не включаются амортизационные отчисления.

$$
\mathrm{c}-\delta=\frac{(\mathrm{r}-\pi+\delta) \times(1-\mathrm{t} \times \mathrm{z}-\mathrm{k})}{(1-\mathrm{t})}-\delta, \text { где }
$$

$\mathrm{c}-\delta-$ стоимость капитала;

$\mathrm{r}$ - номинальная ставка дисконтирования (ставка ожидаемого дохода, при котором владелец капитала согласен инвестировать);

$\pi$ - ожидаемый уровень инфляции;

$\delta$ - норма амортизации;

$\mathrm{z}$ - норма амортизации, используемая в целях налогообложения;

$\mathrm{k}$ - ставка инвестиционного налогового кредита;

$\mathrm{t}$ - законодательно установленная ставка налога на доход.

При этом $\mathrm{r}-\pi-$ реальная ставка дисконтирования находится по модифицированной формуле средневзвешенной стоимости капитала (WACC), где также как и в классической формуле для определения требуемой доходности акции используется модель ценообразования на капитальные активы (САРМ).

$$
r-\pi=f \times(i \times(1-\lambda \times t)-\pi)+(1-f) \times E, \text { где }
$$

$\mathrm{r}$ - номинальная ставка дисконтирования;

$\pi$ - ожидаемый уровень инфляции;

$\mathrm{t}$ - законодательно установленная ставка налога на доход;

f - доля инвестиций, финансируемых за счет заемных средств;

i - номинальная процентная ставка;

Е - реальная прибыль на акцию;

$\lambda$ - доля процентных расходов, подлежащих вычету при расчете налоговой базы.

Однако в отличие от стандартной формулы берется не номинальная доходность акций отдельной компании, а долгосрочная историческая средняя реальная прибыль на акцию крупных компаний. Также при расчете используется не номинальная, а ожидаемая реальная процентная ставка. При этом веса, по которым взвешиваются прибыль на акцию и процентная ставка, определяются как доля инвестиций, финансируемых за счет собственных и заемных средств. В США при расчете предельной эффективной стаки предполагается, что коэффициент финансового левериджа остается постоянным, и установлена доля инвестиций, финансируемых за счет привлечения заемных ресурсов, отдельно для корпоративного $(0,4059)$ и некорпоративного секторов $(0,2734)$ [2].

Стоимость заемного капитала корректируется с учетом ставки налога на прибыль, поскольку проценты по кредиту подлежат вычету из налоговой базы, то есть, учитывается так называемый процентный налоговый щит (сумма сэкономленных налоговых обязательств). Однако в отличие от стандартной формулы WACC при расчете налогового щита налоговая ставка дополнительно корректируется на долю процентных расходов, которые подлежат вычету.

Далее уделим внимание порядку определения реальной отдачи инвестиций после налогообложения.

$$
\begin{gathered}
s=c_{d} \times\left[i \times\left(1-t_{d}\right)\right]+c_{r e} \times\left[i \times(1-t) \times\left(1-t_{r e}\right)\right]+c_{n s} \times \\
{\left[i \times(1-t) \times\left(1-t_{n s}\right)\right]-\pi, \text { где }}
\end{gathered}
$$

$\mathrm{s}-$ средневзвешенная реальная доходность инвестиций, финансируемых собственным и заемным капиталом; 
t - ставка налога на корпоративный доход;

$\mathrm{td}$-ставка налога на процентный доход;

tre - ставка налога на прирост капитальной стоимости;

tns - ставка налога на дивидендный доход;

$\mathrm{cd}$ - доля инвестиций, финансируемых заемным капиталом;

cre - доля инвестиций, финансируемых за счет нераспределенной прибыли;

cns - доля инвестиций, финансируемых за счет выпуска новых акций.

Данная формула позволяет определить совокупную реальную доходность инвестиций после налогообложения в корпоративном секторе, а именно доходность, получаемую кредиторами корпорации и акционерами [3]. При этом учитывается не только корпоративный, но и индивидуальный уровень налогообложения посредством включения в формулу ставок налога на процентный доход, на прирост капитальной стоимости и дивидендный доход. Так выражения $\mathrm{i} \times(1-\mathrm{t}) \times\left(1-\mathrm{t}_{\mathrm{re}}\right)$ и $\mathrm{i} \times(1-\mathrm{t}) \times$ $\left(1-t_{\mathrm{ns}}\right)$ позволяют определить чистую доходность акционеров. Подобная математическая запись соответствует так называемому «двойному налогообложению», характерному для корпоративного сектора, когда один и тот же доход сначала облагается корпоративным, а затем индивидуальными налогами. Выше приведенная формула исходит из предположения, принятого в модели стоимости капитала, о безубыточности инвестиций, в соответствии с которым инвестиции после налогообложения должны обеспечить корпорации уровень рентабельности, по крайней мере, равный стоимости заемных ресурсов (i). Так в исследовании, поведенном Бюджетным комитетом Конгресса США, применялась ставка равная 5\% [1].

В США модель стоимости капитала используется для того, чтобы получить предельную эффективную налоговую ставку для 76 видов амортизируемых активов (оборудование, сооружения, нематериальные активы).

В модели некоторые ключевые параметры, такие как темп инфляции (среднее значения дефлятора ВВП за прогнозный период, равный десяти годам), законодательно установленная налоговая ставка (исходя из базового прогноза доходов бюджета), номинальная процентная ставка (средняя ключевая ставка за прогнозный период, равный десяти годам) и реальная прибыль на акцию до налогообложения (долгосрочная историческая средняя реальная прибыль на акцию крупных компаний) имеют одинаковые значения для всех активов и секторов.

Кроме того, для каждого актива определяется экономическая норма амортизации и метод начисления амортизации в целях налогообложения. В налоговых целях активы амортизируются на основе метода модифицированного ускоренного восстановления стоимости (MACRS), в соответствии с которым для каждого актива предусмотрен свой максимальной срок полезного использования $(3,5 ; 7 ; 10 ; 15 ; 20 ; 25$; 27,5 и 39) и один из трех методов амортизации: линейный метод; метод уменьшаемого остатка с переходом к линейному методу, где коэффициент ускоренной амортизации равен 1,5 (DBSL (150)); метод уменьшаемого остатка с переходом к линейному методу, где коэффициент ускоренной амортизации равен 2 (DBSL (200)). Согласно действующему законодательству США, текущая стоимость амортизационных отчислений в налоговых целях превосходит фактическую величину потребления основного капитала в экономике. Это достигается именно за счет постепенного перехода от метода уменьшаемого остатка к линейному методу по мере того, как амортизация, рассчитанная методом уменьшаемого остатка, становится ниже величины амортизационных отчислений, рассчитанных линейным методом. Например, когда 
рассчитывается текущая стоимость амортизационных отчислений в налоговых целях, то в рамках модели стоимости капитала предполагается, что срок эксплуатации сооружений в сельском хозяйстве составляет не более 20 лет и используется метод DBSL (150).

Изложив ключевые теоретические аспекты, предлагаем вернуться к докладу, подготовленному Бюджетным комитетом Конгресса США, где были представлены значения предельных эффективных налоговых ставок для стран «Большой двадцатки» (табл. 3).

Таблица 3

Предельная эффективная налоговая ставка, \%

\begin{tabular}{|c|c|}
\hline Страна & Значение \\
\hline Аргентина & 22,6 \\
\hline Япония & 21,7 \\
\hline Соединенное Королевство & 18,7 \\
\hline США & 18,6 \\
\hline Бразилия & 17 \\
\hline Германия & 15,5 \\
\hline Индия & 13,6 \\
\hline Мексика & 11,9 \\
\hline Индонезия & 11,8 \\
\hline Франция & 11,2 \\
\hline Австралия & 10,4 \\
\hline Китай & 10 \\
\hline ЮАР & 9 \\
\hline Канада & 8,5 \\
\hline Саудовская Аравия & 8,4 \\
\hline Турция & 5,1 \\
\hline Россия & 4,4 \\
\hline Южная Корея & 4,1 \\
\hline Италия & $-23,5$ \\
\hline
\end{tabular}

В докладе отмечается, что одним из значимых факторов, влияющих на разброс предельных ставок, является соотношение собственных и заемных средств. Дело в том, что в большинстве стран компании могут из налогооблагаемого дохода вычитать процентные платежи по кредиту, а не дивиденды, выплачиваемые акционерам (в Бразилии и Италии разрешаются и вычеты дивидендов, в результате в Италии предельная эффективная ставка оказалась отрицательной). В связи с чем, предельная эффективная ставка при финансировании инвестиций заемным капиталом ниже, чем при финансировании собственным капиталом. При этом, чем выше законодательная налоговая ставка и уровень инфляции, тем выше значение процентного налогового щита. Среди стран ЕС доля инвестиций, финансируемых заемными ресурсами, составляет от 40\% в Люксембурге до 68\% в Италии (в Германии - 63\%, Франции $58 \%$, Южной Кореи - 66\%) [1].

В межстрановых сравнениях, проводимых Бюджетным комитетом, предельная эффективная ставка оценивалась исходя из следующего соотношения заемного и собственного капитала: акционерный капитал - 65\%, заемный капитал - 35\% [1]. Затем рассматривался вариант, когда инвестиции финансировались исключительно собственными средствами, в результате предельные ставки во всех странах выросли, поскольку не учитывались процентные вычеты. Можно привести конкретные цифры. 
Так в США в случае, когда инвестиции финансировались только акционерным капиталом, предельная эффективная ставка для зданий и сооружений составила $40 \%$, а для оборудования - 28\%, если использовались оба источника финансирования, то предельная ставка снизилась до $26 \%$ для зданий и сооружений и до $11 \%$ для оборудования.

Кроме коэффициента финансового левериджа, важной детерминантой предельной эффективной налоговой ставки выступает норма амортизации. В 14 странах «Большой двадцатки» амортизационные отчисления в целях налогообложения были выше экономической амортизации. В данном исследовании при оценке предельной эффективной ставки для всех стран были установлены следующие нормы экономической амортизации: 3,1\% - для сооружений, 17,5\% - для оборудования, 15,3\% - для нематериальных активов [1]. Так в Индии, согласно положениям налогового кодекса, амортизация в налоговых целях превышала экономическую амортизацию почти на 60\%, в семи других странах это превышение составило около 40\%. Стоит отметить и тот факт, что в 11 странах более щедрые амортизационные отчисления, разрешенные к вычету из налогооблагаемого дохода, предоставляются для оборудования, нежели чем для зданий и сооружений. В 2011 г. в Соединенном Королевстве амортизация на недвижимое имущество была отменена вовсе. Предельная эффективная ставка на оборудование оказалась ниже, чем на недвижимое имущество в США, Японии, Канаде, Соединенном Королевстве. Обратная ситуация характерна для Китая, Индии и Индонезии, где наибольшие вычеты по амортизации предоставляются для зданий и сооружений. Наконец, в Аргентине, которая имеет самую высокую предельную эффективную ставку, амортизационные отчисления, признаваемые в налоговых целях, были ниже экономической амортизации как по оборудованию, так и по недвижимому имуществу. Таким образом, можно заключить, что предельная эффективная налоговая ставка выступает инструментом оценки влияния изменений в налоговой политике на уровень налогообложения различных активов.

$$
* * *
$$

1. [Электронный ресурс] URL: https://www.cbo.gov/system/files/115th-congress-2017-2018/reports/52419internationaltaxratecomp.pdf (дата обращения 11.12.2017).

2. [Электронный pecypc] URL: https://www.treasury.gov/resource-center/tax-policy/taxanalysis/Documents/New-Investment-Rates-Methodology.pdf (дата обращения 02.01.2018).

3. [Электронный ресурc] URL: https://www.urban.org/sites/default/files/alfresco/publication-pdfs/1000538Marginal-Effective-Tax-Rate.PDF (дата обращения 28.01.2018).

Рубцова В.E.

\section{Принципы бухгалтерского учета}

Новосибирский государственный университет экономики и управления«НИНХ» (Россия, Новосибирск)

doi:10.18411/spc-8-03-2018-12

idsp: 000001:spc-8-03-2018-12

В целях обеспечения единообразного подхода к организации бухгалтерского учета на всех хозяйствующих субъектах в российском законодательстве разработаны основные принципы его организации, использование которых является обязательным при осуществлении бухгалтерского учета.

Сущность принципов бухгалтерского учета заключается в том, что они представляют собой универсальные нормы организации бухгалтерского учета и отражения в нем хозяйственных операций экономического субъекта. 